\title{
Hesitant Cloud Model and Its Application in the Risk Assessment of "The Twenty-First Century Maritime Silk Road"
}

\author{
Lizhi Yang, ${ }^{1}$ Ren Zhang, ${ }^{1,2}$ Taiping Hou, ${ }^{1}$ Zhinan Hao, ${ }^{1}$ and Jun Liu ${ }^{3}$ \\ ${ }^{1}$ PLA University of Science and Technology, Meteorological and Oceanographic Institution, Nanjing 211101, China \\ ${ }^{2}$ Collaborative Innovation Center on Forecast Meteorological Disaster Warning and Assessment, \\ Nanjing University of Information Science \& Technology, Nanjing 210044, China \\ ${ }^{3}$ Chengdu Military Area Command, Surveying and Mapping Information Center, Chengdu 610000, China
}

Correspondence should be addressed to Ren Zhang; zrpaper@163.com

Received 9 November 2015; Accepted 8 March 2016

Academic Editor: Laura Gardini

Copyright (C) 2016 Lizhi Yang et al. This is an open access article distributed under the Creative Commons Attribution License, which permits unrestricted use, distribution, and reproduction in any medium, provided the original work is properly cited.

\begin{abstract}
The evaluation of human environment risk is lacking quantitative data, while the qualitative knowledge cannot be easily quantified and synthesized. Furthermore, sometimes the experts are not well acknowledged with the whole indicator system or cannot reach an agreement on the comments. The conventional evaluation methods are not competent to solve the above aporia effectively. Thus the quantization of the human environment risk becomes a conundrum. The compatibility cloud model theory can set up a conversion model between the qualitative knowledge and quantitative value, which provides technique approaches to evaluating the risk of human environment. However, the hesitant opinion of experts stemming from the missing knowledge of the whole system or the branching opinions cannot be well solved by the traditional compatibility cloud model theory. Therefore, this paper brings in the theory of hesitant fuzzy set, combining with the cloud model theory, to try to construct a hesitant cloud model to achieve the quantitative assessment of human environment risk. And at last an experiment evaluation on the risk of maritime silk road is carried out.
\end{abstract}

\section{Introduction}

Human environment risk such as political risk can only get access to some paperwork when it is quantitatively evaluated. There is always plenty of useful information involving different aspects and levels in the miscellaneous paperwork. As a result, if there is no mapping model from qualitative data to quantitative value, the merging of this useful information will be extremely difficult. The earliest techniques to cope with the above conundrum are expert scoring method and analytic hierarchy process while they are always criticized owing to their grave subjectivity. For example, the distinctions between the values graded are totally decided by the subjective sense of experts; that is, a single value means different varying with different experts; like "0.8" may mean "very good" with expert A while it may mean "just good" with expert B. Therefore, to deal with such uncertainty in risk analysis and assessment process, Nishiwaki et al. [1] firstly propose the possible application of fuzzy set theory in risk assessment. After that,
Pokorádi [2], Dutta and Ali [3], Arunraj et al. [4], and Chen et al. [5] have explored such application deeply. Expert can choose the mathematical form that represents his evaluation via establishing membership function based on the fuzzy set theory, which is more reasonable than expert scoring method and analytical hierarchy process. However, with there being no objective criterion and basis for the choosing of membership function, it is usually done with experts' sense of subjectivity. Moreover, the uncertainty of language concept contains two facets virtually, fuzziness and randomness [6], while only the fuzziness of expert comments can be expressed by the application of fuzzy set theory in risk assessment.

To establish the mapping model from qualitative data to quantitative value and cope with both "fuzziness" and "randomness" in language, academician Li [7] has set up the compatibility cloud to construct the conversion model between the qualitative data and quantitative value, which promote the research about the relationship between the connotation and extension of the human cognition concept. After that, 
the cloud model theory has been more rich and perfect thanks to the work of the research team of $\mathrm{Li}[6,8,9]$. Because of its advantage in dealing with the conversion between the qualitative data and quantitative value, the compatibility cloud model theory has been prevalent in artificial intelligence field.

However, two situations often occur in the course of evaluation as follows: (i) limiting the range of his professional knowledge and the understanding degree about the object, expert cannot make his comment on part of the indicators; for example, there are seven evaluation indicators for one object, but the expert can only make comments on five indicators. (ii) Because of the hesitation between two variant comments, an expert cannot make a single and certain comment on one object; for instance, the expert may give two comments on one indicator because of his consideration about its property lying between "medium" and "moderately good." The traditional methods for evaluation are of single value. That is to say, one expert must make comments, respectively, on all indicators. Besides, in conventional ways, a compromise would be the choice in the process of dealing with multiexperts' comments. Therefore the traditional methods cannot be a good solution to the above problem. As the development of fuzzy mathematics, Torra and Narukawa have proposed hesitant fuzzy sets in 2009, which is an expansion of the fuzzy sets theory. Several possible values are tolerated in the membership of a single element which is the core idea of it. Torra and Narukawa $[10,11]$ have defined the hesitant fuzzy set and some of its basic operations; Xu and Xia [12, 13], Zhu et al. [14], Chen and Xu [15], and González-Arteaga et al. [16] have done great effort to improve and perfect its system info; Rodríguez et al. $[17,18]$ have provided an overview of the current extensions of the theory and some of the most important trends or challenges that should be achieved in such topics. The two difficulties in the course of evaluation can be well solved by the application of hesitant fuzzy set. Therefore it is gradually introduced into the research field of decision-making in recent years [19-22].

To sum up, it is difficult to quantify the qualitative data in human environment risk assessment, due to the lack of a model to convert the comments of experts to quantitative value. Moreover, in the process of human environment risk assessment, the knowledge of experts is always not comprehensive, and the judgement of experts on one object is hesitant. In view of above problems, this paper will construct a hesitant cloud model based upon hesitant fuzzy set and cloud model theory to make assessment on human environment risk, and a proper example will be brought in to test the practicability of this model.

\section{Principle and Theoretical Basis of Method}

2.1. Cloud Model Theory. The uncertainty of linguistic atoms contains two characters-randomness and fuzziness [6]. However, only one character is involved in the existing mathematical methods, like the probability theory dealing with randomness and the fuzzy set disposing fuzziness. To quantitatively represent the linguistic terms and effectively integrate the fuzziness and randomness of a linguistic term in a unified way, academician Li [7] proposed the theory of membership

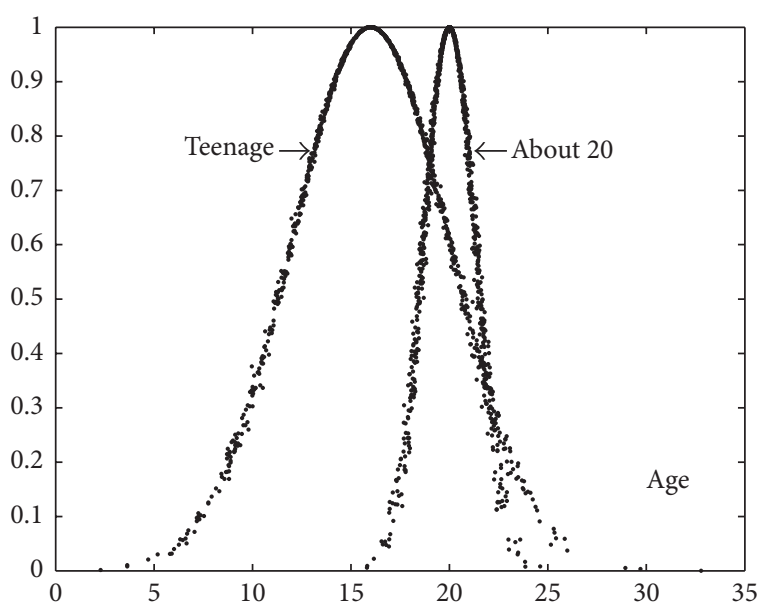

FIgURE 1: The clouds for various linguistic terms of "Ages."

cloud based on probability theory and fuzzy set, whose basic idea is to let $U$ be the set, $U=\{u\}$, as the universe of discourse, and $A$ a linguistic term associated with $U$. As $u$ is a random implementation of $A$, the membership degree of $u$ in $U$ to the linguistic term $A, C_{A}(u)$, is a random number with a stable tendency. $C_{A}(u)$ takes the values in $[0,1]$. A compatibility cloud is a mapping from the universe of discourse $U$ to the unit interval $[0,1]$. That is,

$$
C_{A}(u): U \longrightarrow[0,1] \quad \forall u \in U, u \longrightarrow C_{A}(u) .
$$

Due to each $u$ being a cloud drop, the overall shape of clouds is the representative of linguist term. Figure 1 shows appropriate compatibility clouds for the linguistic terms "about 20" and "teenage" from the term-set of the linguistic variable "Age."

As Figure 1 shows, the compatibility is not just a membership curve, and the mapping from all $u \in U$ to the interval $[0,1]$ is one-point to multipoint transition. Such characteristic makes itself precede the traditional fuzzy set, whose one-point-to-one-point rule has made the uncertainty of an element belonging to the fuzzy concept become certain to a degree with a precise number. With the model of compatibility clouds, soft computing may be implemented to exploit the tolerance and inheritance for uncertainty and imprecision. Besides, the definition of compatible cloud integrates the randomness and fuzziness via such concise concept as "random implementation" and "membership degree." Each cloud drop is a random event, while the membership of that drop involves fuzziness, and the membership is a random value itself. The larger the probability of the random $u$ is, the greater the membership is, which means that cloud would contribute more to the concept of linguistic term. The overall shape of the qualitative concept will be better represented by more cloud droplet.

The qualitative linguistic concepts are always too complex and uncertain to be described in precise quantitative terms, which is more easily amenable in the process of evaluation. However, the compatibility cloud has been a transition model to provide a means of its representation and meanwhile avoid expressing it by the use of complicated mathematical 
operations to keep the pure nature of human thought, so that it can be better represented as quantitative values. Owing to its excellence, the models based on compatibility cloud are prevalent in subjective evaluation $[23,24]$. At present, the normal cloud model is the most popular cloud model because of the universalities of normal distribution and bell-shaped membership function in every branch of both social sciences (such as psychology, industry, commerce, and linguistics) and natural sciences [6].

The construction of cloud model based on compatibility cloud theory comes to three vital theoretical bases: digital characteristics of cloud model, cloud integration, and cloud generator.

2.1.1. Digital Characteristics of Cloud Model. The quantitative features (compatibility cloud) of the qualitative linguistic concept are always represented by three digital characteristics: (Ex, En, He).

(1) Expectation (Ex) of a compatibility cloud is the position at $U$ corresponding to the center of gravity of the cloud. It is most fully compatible with the linguistic concept, such as 20 which is the expectation of the linguistic concept "about 20."

(2) Entropy (En) is the metric of the uncertainty of the concept within the universe of discourse. Firstly, it is the measure of the fuzziness, showing how many elements in the universe of discourse could be accepted to the linguistic concept; secondly, it is also the measure of the randomness, showing the dispersion degree of the cloud drops; at last, it reflects the relevance of the fuzziness and randomness. Generally, the larger the entropy is, the greater the uncertainty is, and it is more difficult for quantization.

(3) Hyperentropy $(\mathrm{He})$ is metric of the uncertainty of the entropy. In other words, it is the entropy of entropy, showing the deviation degree from the normal distribution. It can be also considered as the measure of the maturity of the cloud model, as it is always provided by the constructer of the model.

2.1.2. Cloud Integration. There is always no exact tree structure with trenchant hierarchy and explicit boundary in the process of human cognition, while there are always many overlaps among these concepts, and a lower-level concept may belong to multiple concepts of upper-level concept. Such structure emerging with tree structure in the universe and net structure in the parts is called pan-concept-tree [25]. The conversion orientation of the granularity of object is ovonic:

(i) one orientation is the inshot from the finer granularities to the coarser granularities, abstracting the knowledge to simplify the issues, which is usually called data reduction;

(ii) the other orientation is from the coarser granularities to the finer ones, by which means the numerous personality traits appear that are more typical than the generality.
Thus, cloud integration is the process of synthesizing two clouds into one cloud, that is, making a direct conversion for the linguistic concept to the desired granularity or hierarchy on the basis of the leaf nodes of pan-concept-tree. In that way, two or more linguistic terms can be synthesized into a more generalized linguistic concept term.

The most commonly used algorithm for cloud computing is the virtual cloud, by which new digital characteristics can be worked out with several given digital characteristics. It can be divided into several kinds like floating-cloud, integrating-cloud, decomposing-cloud, and geometrical-cloud. Among them, the floating-cloud and integrating-cloud are the frequently used algorithms for cloud integration; the decomposing-cloud algorithm is inverted to the integratingcloud, decomposing one cloud into several clouds to depict the concept to be more detailed and refine it; geometricalcloud is an approach to fitting a complete cloud based on some partial features [6].

Then, the two kinds of cloud integration methods will be introduced as follows.

(1) Floating-Cloud Algorithm. By floating-cloud, virtual linguistic terms can be generated to cover the blank area between two original clouds. Thus it is especially appropriate for the indicators which are relatively independent on each other. The following formula shows its calculation:

$$
\begin{aligned}
\mathrm{Ex}= & \frac{\mathrm{Ex}_{1} W_{1}+\mathrm{Ex}_{2} W_{2}+\cdots+\mathrm{Ex}_{n} W_{n}}{W_{1}+W_{2}+\cdots+W_{n}}, \\
\mathrm{En}= & \frac{W_{1}^{2}}{W_{1}^{2}+W_{2}^{2}+\cdots+W_{n}^{2}} \cdot \mathrm{En}_{1}+\cdots \\
& +\frac{W_{n}^{2}}{W_{1}^{2}+W_{2}^{2}+\cdots+W_{n}^{2}} \cdot \mathrm{En}_{n}, \\
\mathrm{He}= & \frac{W_{1}^{2}}{W_{1}^{2}+W_{2}^{2}+\cdots+W_{n}^{2}} \cdot \mathrm{He}_{1}+\cdots \\
& +\frac{W_{n}^{2}}{W_{1}^{2}+W_{2}^{2}+\cdots+W_{n}^{2}} \cdot \mathrm{He}_{n} .
\end{aligned}
$$

(2) Integrating-Cloud Algorithm. Several original clouds can be merged into an extensive cloud representing the more generalized linguistic terms by integrating-cloud algorithm, which would be well applied to synthesis of the indicators that are interrelated with each other. The integrated cloud will cover a longer extension. "Soft or" algorithm shown as in formula (3) would be the most commonly used one in integrating-cloud algorithm.

Let two adjacent clouds be $C_{1}\left(\mathrm{Ex}_{1}, \mathrm{En}_{1}, \mathrm{He}_{1}\right)$ and $C_{2}\left(\mathrm{Ex}_{2}\right.$, $\mathrm{En}_{2}, \mathrm{He}_{2}$ ). If $\mathrm{Ex}_{1} \leq \mathrm{Ex}_{2}$, then the integrated cloud can be depicted as $C_{3}=C_{1} \cup C_{2}$, with the characteristics of $C_{3}\left(E_{3}\right.$, $\mathrm{En}_{3}, \mathrm{He}_{3}$ ) being

$$
\begin{aligned}
\mathrm{Ex}_{3} & =\frac{\mathrm{Ex}_{1}+\mathrm{Ex}_{2}}{2}+\frac{\mathrm{En}_{2}-\mathrm{En}_{1}}{4}, \\
\mathrm{En}_{3} & =\frac{\mathrm{Ex}_{2}-\mathrm{Ex}_{1}}{4}+\frac{\mathrm{En}_{1}+\mathrm{En}_{2}}{2}, \\
\mathrm{He}_{3} & =\max \left(\mathrm{He}_{1}, \mathrm{He}_{2}\right)
\end{aligned}
$$




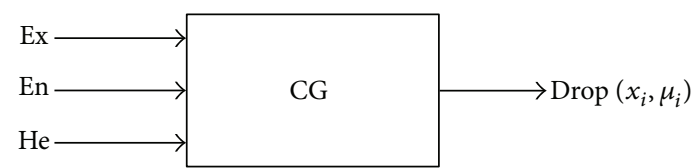

Figure 2: The forward normal cloud generator.

2.1.3. Cloud Generator. Normal compatibility cloud is a special form, and the normal distribution is usually represented by two digital characteristics mean-value and variance, while the bell-shaped membership function is often depicted as $\mu(x)=e^{-(x-a)^{2} / 2 b^{2}}$. Then, the core idea of normal compatibility cloud is supposed as follows: let $U$ be the set, $U=\{x\}$, as the universe of discourse, and $A$ a linguistic term associated with $U$. As $x$ is a random implementation of $A$, it always obeys the normal distribution $N\left(E x, E^{\prime 2}\right)$, in which $\mathrm{En}^{\prime}$ obeys normal distribution $N\left(\mathrm{En}, \mathrm{He}^{2}\right)$. The membership degree of $x$ in $U$ to the linguistic term $A$ is $\mu=e^{-(x-\operatorname{Ex})^{2} / 2\left(\operatorname{En}^{\prime}\right)^{2}}$; therefore, the distribution of $x$ on $A$ can be considered as a normal cloud.

Cloud generators can be divided into a forward one and converse one. Cloud droplets can be generated by the forward cloud generator with three characteristics (Ex, En, He). Thus the mapping from qualitative concept to quantitative data can be achieved. Figure 2 shows the keystone of forward normal cloud generator, and the algorithm is as follows:

(A) Generate a normal random value En' with En as the expectation and $\mathrm{He}^{2}$ as the variance.

(B) Generate a normal random value $x$ with En as the expectation and $\mathrm{En}^{\prime 2}$ as the variance.

(C) Calculate $\mu\left(x_{i}\right)=e^{-\left(x_{i}-\mathrm{Ex}\right)^{2} / 2\left(\mathrm{En}_{i}^{\prime}\right)^{2}}$.

(D) Generate $x_{i}$ with membership degree $\mu\left(x_{i}\right)$ as the cloud droplets in the number field.

(E) Repeat the above steps until the required amount of cloud droplets are generated.

2.2. Hesitant Fuzzy Set. Since the theory of fuzzy sets has been proposed by Zadeh in 1965, it has been developed rapidly and used widely in various disciplines. Then, researchers have put forward several models like intuitionistic fuzzy sets [26] and interval valued fuzzy sets [27] to promote the development of fuzzy sets. However, in the process of practical decisionmaking, the decision makers are usually hesitant within several alternatives when they make comments on the target. Such aporia cannot be well solved by the extension models referred to above effectively. Therefore, Torra and Narukawa have proposed hesitant fuzzy sets in 2009 [10] shown as in Definition 1.

Definition 1. Let $A=\left\{h_{1}, h_{2}, \ldots, h_{n}\right\}$ be a set of $n$ HFEs and $\vartheta$ a function on $A, \vartheta:[0,1]^{n} \rightarrow[0,1]$; then $\vartheta_{A}=$ $\bigcup_{\gamma \in\left\{h_{1} \times h_{2} \times \cdots \times h_{n}\right\}}\{\vartheta(\gamma)\}$.

On the basis of the theory of conventional fuzzy set, several possible values are tolerated by the membership of a single element in hesitant fuzzy sets. Currently, it is widely used in the decision-making area, because of the adaptability to deal with the distinction of domain-knowledge width of multiple decision makers and the difference of cognition degree on the object of one decision maker. Since it has been put forward, many researchers in different domain have delved into hesitant fuzzy sets. As a result, its theoretics and applications have been developed rapidly. Professor Xu has made a great contribution to hesitant fuzzy set: she has defined a series of measures for distance and similarity of hesitant fuzzy sets, hesitant fuzzy entropy, several algebraic operations, and aggregation operators such as "hesitant fuzzy weighted averaging (HFWA) operator," "hesitant fuzzy weighted geometric (HFWG) operator," "hesitant fuzzy ordered weighted averaging (HFOWA) operator," and "hesitant fuzzy ordered weighted geometric (HFOWG) operator" $[12,13,28]$. Due to the dramatical growth of hesitant fuzzy set, Rodríguez et al. [17] have presented an overview on hesitant fuzzy sets to provide a distinct perspective on the different concepts, tools, and trends related to this extension of fuzzy sets. They have pointed out that a new trend of further research is the application of the theoretical models to real problems; that is, the proposed models must be justified from a theoretical or practical point of view and solve real problems with uncertainty. Then, with diverse extensions of hesitant fuzzy sets that have been proposed, Rodríguez et al. [18] have recognized that some of these proposals are mistaken regarding hesitant fuzzy sets. Some proposals which present human knowledge are debatable, because they are just a mathematical extension and do not go in depth in the theory. So they provide a discussion about current proposals and some challenges of hesitant fuzzy sets. It is worthy of mentioning that, as its trend in real applications, they have pointed out that the aggregation operators should also be driven by real applications or deep mathematical properties.

2.3. Existing Problems. The cloud model can be applied to deal with the aporia of conversion between qualitative linguistic terms and quantitative values. However, in the process of evaluation, assessors are always hesitant in the characteristics of several indicators to make a certain comment on these indicators. Or there is another situation that one object would be evaluated by several assessors, who will make distinct comments on some indicators of that object, which means indicators may get different numbers of comments. The above problems can be well solved by hesitant fuzzy sets. Therefore, the next section will construct a hesitant cloud model based on the classical mathematical theory of cloud model and hesitant fuzzy sets, in purpose of coping with the aporia of the human environment risk assessment.

\section{The Hesitant Cloud Model}

3.1. Model Construction. The hesitant cloud model is based on the theory of compatibility cloud and hesitant fuzzy sets to achieve evaluation of risk. The steps of modeling are as follows.

Step 1 (construct comments set). According to the judgement on the indicators set $\left\{B_{i}\right\}$ of evaluated object, $i=1,2, \ldots, n$, 


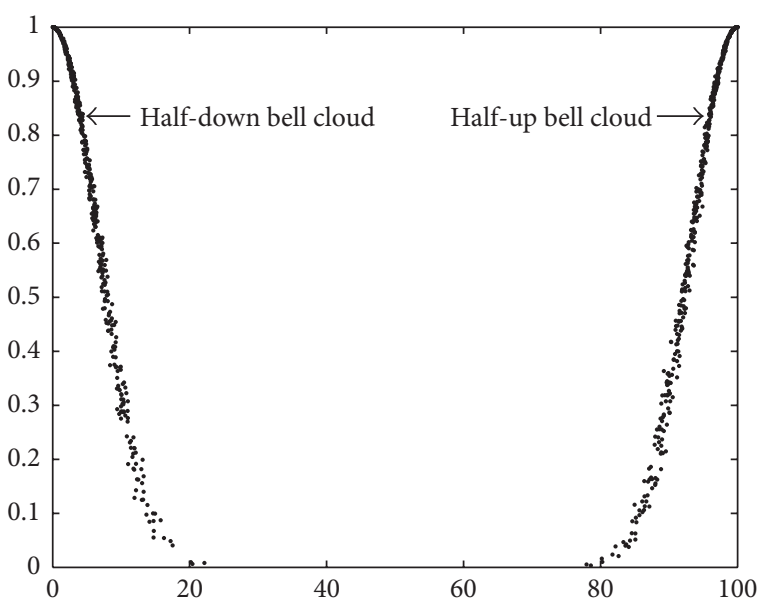

Figure 3: The half-down and half-up bell cloud.

the assessors make the comments on these indicators as $\left\{C_{j_{k}}\right\}$, $j_{k}=1,2, \ldots, m_{k}$, and $m_{k} \leq n$. Then the matrix of comments of $k$ experts can be obtained as $\left\{C_{1 j_{1}}, C_{2 j_{2}}, \ldots, C_{k j_{k}}\right\}$.

Step 2 (set up linguistic quantifiers). According to the normal cloud compatibility, among the comments set such linguistic terms like "lower," "medium," and "higher" are restricted by bilateral boundaries, whose shape is a full bell. The lower boundary can be set as $a$ and the upper boundary as $b$; thus such linguistic terms will be quantified by formula (4). $k$ is a constant value which represents the maturity of this model and is decided by the experts. However, such linguistic terms as "extreme low" and "extreme high" reach the left of the right boundary of the universe of discourse; thus the bell shape of the cloud becomes a half-down or half-up bell cloud as Figure 3 shows.

To represent these linguistic terms, the boundary value $a$ or $b$ can be set as Ex; then it will be quantified by formula (5). Consider the following:

$$
\begin{aligned}
& \mathrm{Ex}=\frac{(a+b)}{2}, \\
& \mathrm{En}=\frac{(b-a)}{6}, \\
& \mathrm{He}=k \\
& \mathrm{Ex}=a \text { or } b, \\
& \mathrm{En}=\frac{(b-a)}{3}, \\
& \mathrm{He}=k .
\end{aligned}
$$

Step 3 (create hesitant cloud set). In the light of linguistic quantifiers of the comments set $\left\{C_{1 j_{1}}, C_{2 j_{2}}, \ldots, C_{k j_{k}}\right\}$, three groups of hesitant fuzzy sets about $n$ indicators would be created as $\left\{h_{11}, h_{12}, \ldots, h_{1 n}\right\},\left\{h_{21}, h_{22}, \ldots, h_{2 n}\right\}$, and $\left\{h_{31}, h_{32}\right.$, $\left.\ldots, h_{3 n}\right\}$, which are, respectively, corresponding to Ex, En, He. Then the hesitant fuzzy elements of three groups of hesitant fuzzy sets will be aggregated, respectively, by HFWA or HFWG operators, which is shown as in Definitions 2 and 3.

Definition 2. Let $h_{i}(i=1,2, \ldots, n)$ be a collection of HFEs. A hesitant fuzzy weighted averaging (HFWA) operator is a mapping $\Theta^{n} \rightarrow \Theta$ such that

$$
\begin{aligned}
& \operatorname{HFWA}\left(h_{1}, h_{2}, \ldots, h_{n}\right)=\bigoplus_{i=1}^{n} w_{i} h_{i} \\
& =\bigcup_{\gamma_{1} \in h_{1}, \gamma_{2} \in h_{2}, \ldots, \gamma_{n} \in h_{n}}\left\{1-\prod_{i=1}^{n}\left(1-\gamma_{i}\right)^{w_{i}}\right\},
\end{aligned}
$$

where $w=\left(w_{1}, w_{2}, \ldots, w_{n}\right)^{T}$ is the weight vector of $h_{i}(i=$ $1,2, \ldots, n)$ with $w_{i} \in[0,1], i=1,2, \ldots, n$, and $\sum_{i=1}^{n} w_{i}=1$. In particular, if $w=(1 / n, 1 / n, \ldots, 1 / n)^{T}$, then the HFWA operator reduces to the hesitant fuzzy averaging (HFA) operator:

$$
\begin{aligned}
\operatorname{HFA} & \left(h_{1}, h_{2}, \ldots, h_{n}\right)=\frac{1}{n} \bigoplus_{i=1}^{n} h_{i} \\
= & \bigcup_{\gamma_{1} \in h_{1}, \gamma_{2} \in h_{2}, \ldots, \gamma_{n} \in h_{n}}\left\{1-\prod_{i=1}^{n}\left(1-\gamma_{i}\right)^{1 / n}\right\} .
\end{aligned}
$$

Definition 3. Let $h_{i}(i=1,2, \ldots, n)$ be a collection of HFEs and let HFWG: $\Theta^{n} \rightarrow \Theta$ if

$$
\begin{gathered}
\operatorname{HFWG}\left(h_{1}, h_{2}, \ldots, h_{n}\right)=\bigotimes_{i=1}^{n} h_{i}{ }^{w_{i}} \\
=\bigcup_{\gamma_{1} \in h_{1}, \gamma_{2} \in h_{2}, \ldots, \gamma_{n} \in h_{n}}\left\{\prod_{i=1}^{n} \gamma_{i}^{w_{i}}\right\} .
\end{gathered}
$$

Then the HFWG is called a hesitant fuzzy weighted geometric (HFWG) operator, where $w=\left(w_{1}, w_{2}, \ldots, w_{n}\right)^{T}$ is the weight vector of $h_{i}(i=1,2, \ldots, n)$ with $w_{i} \in[0,1], i=1,2, \ldots, n$, and $\sum_{i=1}^{n} w_{i}=1$. In the case where $w=(1 / n, 1 / n, \ldots, 1 / n)^{T}$, the HFWG operator reduces to the hesitant fuzzy geometric (HFG) operator:

$$
\begin{aligned}
\operatorname{HFG}\left(h_{1}, h_{2}, \ldots, h_{n}\right) & =\bigotimes_{i=1}^{n} h_{i}^{1 / n} \\
& =\bigcup_{\gamma_{1} \in h_{1}, \gamma_{2} \in h_{2}, \ldots, \gamma_{n} \in h_{n}}\left\{\prod_{i=1}^{n} \gamma_{i}^{1 / n}\right\} .
\end{aligned}
$$

On the basis of these hesitant fuzzy sets $\{\mathrm{HEx}\},\{\mathrm{HEn}\}$, $\{\mathrm{HHe}\}$ of Ex, En, He, the hesitant cloud sets $\{\mathrm{HEx}, \mathrm{HEn}, \mathrm{HHe}\}$ can be obtained. If there were $k_{i}$ experts making the comments on the $i$ th indicator, the length of hesitant cloud set is $l=\prod_{i=1}^{n} k_{i}$.

Step 4 (generate compositive cloud). Comparing Exs of two adjacent clouds of the hesitant cloud set $\left\{C_{1}\left(E_{1}, E_{1}, H_{1}\right)\right.$, $\left.C_{2}\left(\mathrm{Ex}_{2}, \mathrm{En}_{2}, \mathrm{He}_{2}\right), \ldots, C_{l}\left(\mathrm{Ex}_{l}, \mathrm{En}_{l}, \mathrm{He}_{l}\right)\right\}$, activing the cloud integration algorithms like floating-cloud or integratingcloud, then a set of compositive cloud contains linguistic comments of all the experts which can be worked out. 


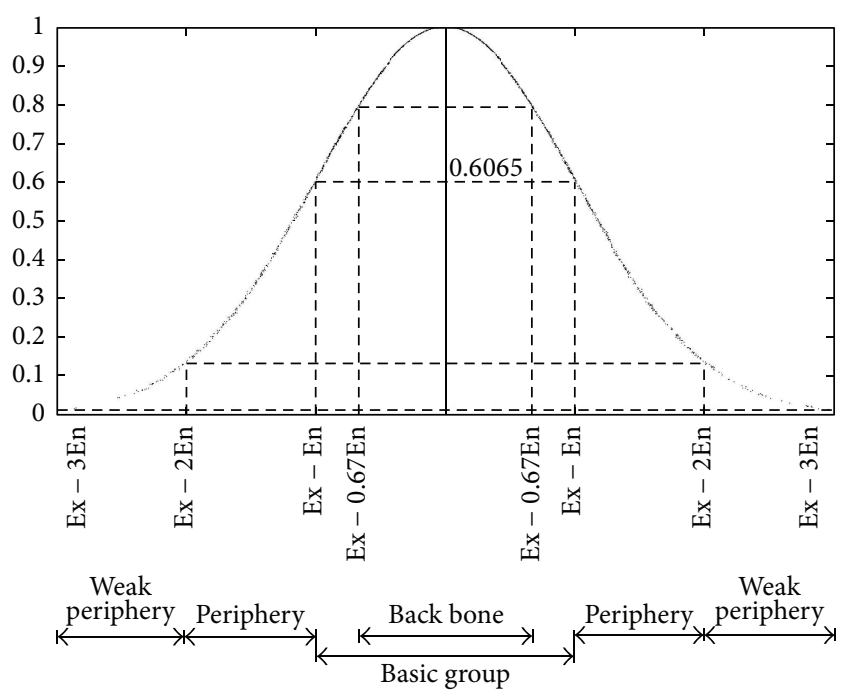

FIGURE 4: Elements of cloud droplets groups.

Step 5 (mapping from digital characteristics to linguistic comments). Create compositive cloud chart by positive normal cloud generator. There will be $n$ cloud droplets composing the whole cloud with different contribution. These cloud droplets are often divided into four kinds as Figure 4 shows [6].

(1) Back Bone. These cloud droplets locate in the interval [Ex - 0.67En, $\mathrm{Ex}+0.67 \mathrm{En}]$, and their contribution to $u$ in the universe of discourse is $50 \%$.

(2) Basic Group. These droplets locate in the interval $[\mathrm{Ex}-\mathrm{En}, \mathrm{Ex}+\mathrm{En}]$, and their contribution to $u$ in the universe of discourse is $68.26 \%$.

(3) Periphery. These cloud droplets locate in the intervals $[E x-2 E n, E x-E n]$ and $[E x+E n, E x+2 E n]$, and their contribution to $u$ in the universe of discourse is $27.18 \%$.

(4) Weak Periphery. These droplets locate in the intervals $[E x-3 E n, E x-2 E n]$ and $[E x+2 E n, E x+3 E n]$, and their contribution to $u$ in the universe of discourse is $4.3 \%$.

In light of the different purpose and required-precision of evaluation, choose the corresponding elements of the whole cloud droplets. Then, the interval of these clouds locating is the result of assessment.

3.2. Selection Principle for Operators. In the above hesitant cloud model, there are two alternative operators that have been referred to: the first one is the hesitant fuzzy aggregation operators, while the other one is the cloud integration algorithms. There are some options for each operator. So the selection of each operator is an inconclusive issue which needs to be explained more clearly. Next, the two operators of the model will be discussed below.

(1) The Selection of Hesitant Fuzzy Aggregation Operators. Because of the correspondence among Ex, En, $\mathrm{He}$ in the order, the HFOWA and HFOWG operators which firstly sort the hesitant fuzzy elements are not applicable so that the HFWA and HFWG operators are chosen to aggregate them as shown in Definitions 2 and 3. The mutual relationship and compensating action among the hesitant fuzzy elements aggregated by the two operators are distinct. The choice of operator is based on its merits and drawbacks and the correlations among the hesitant fuzzy elements. The HFWA operator applies to such hesitant fuzzy elements which are relatively independent from each other or make linear compensation among them. For these elements, a single element is not sensitive to the alteration of other elements. Dissimilarly, the HFWG operator is applicable to aggregate the elements that are correlative and lack compensation with each other. For these operators, a single element is sensitive to the alteration of other elements.

(2) The Selection of Cloud Integration Algorithm. The cloud integration algorithms can be divided into floating-cloud algorithm and integrating-cloud algorithm. The choice of the appropriate integration algorithm is based on the relationship between original clouds and the purpose of the cloud integration. The floating-cloud algorithm can create a new cloud covering the blank areas of original cloud distribution. It is suitable to deal with the original clouds that are independent. A cloud with new linguistic concept will be generated by it, and the entropy of the new cloud is similar to the entropy of original clouds. Making an analogy, it is to some extent similar to " $\cap$ " in arithmetical operation. Being different, the integrating-cloud algorithm will generate a new cloud that covers all the linguistic concept of the original clouds. It is appropriate to cope with such interdependent original clouds. The generated new cloud will cover a more large scope of the universe, and its entropy would be greater than that of original clouds, which means the uncertainty of it will increase. The integrating-cloud algorithm can be analogy as " $U$ " in arithmetical operation.

\section{Model Test and Application}

4.1. Case Selection. "The Twenty-First Century Maritime Silk Road" is a major strategic thought in China on the background of the new era, which is relying on the ASEAN and its member states, deepening the relationships with surroundings and South Asia, and cooperating with Middle East, East Africa, and Europe. Some researches have pointed out that there are many challenges in the construction of the new silk road. What is more, so many countries are lying along it such that the long-term investment environments are extraordinarily uncertain. Some countries are trapped in the game of power countries, and domestic contradictions such as democratic political transition and ethnic conflicts are current. However, this analysis only comes to qualitative discussion and lacks necessary quantitative assessment.

The influencing factors and process mechanism of the human environmental risk of "The Twenty-First Century Maritime Silk Road" are complicated. Besides, most of the humanity knowledge is depicted with language terms, which is too difficult to quantify. When experts make comments on 
TABLE 1: Indicator system for human environment risk of The Twenty-First Century Maritime Silk Road.

\begin{tabular}{|c|c|c|c|}
\hline Target layer (A) & First indicator layer (B) & Secondary indicator layer (C) & Indicator property \\
\hline \multirow{13}{*}{$\begin{array}{l}\text { Human environment risk of } \\
\text { The Twenty-First Century } \\
\text { Maritime Silk Road (A1) }\end{array}$} & \multirow{5}{*}{ Political situation (B1) } & State failure instability event $(\mathrm{Cl})$ & $\begin{array}{l}\text { The better the index comment, } \\
\text { the greater the risk }\end{array}$ \\
\hline & & State failure internal war event $(\mathrm{C} 2)$ & $\begin{array}{l}\text { The better the index comment, } \\
\text { the greater the risk }\end{array}$ \\
\hline & & Governance corruption (C3) & $\begin{array}{l}\text { The better the index comment, } \\
\text { the greater the risk }\end{array}$ \\
\hline & & Governance effectiveness (C4) & $\begin{array}{l}\text { The better the index comment, } \\
\text { the lesser the risk }\end{array}$ \\
\hline & & Terrorism activity (C5) & $\begin{array}{l}\text { The better the index comment, } \\
\text { the greater the risk }\end{array}$ \\
\hline & \multirow{5}{*}{ Economic situation (B2) } & Poverty population ratio (C6) & $\begin{array}{l}\text { The better the index comment, } \\
\text { the greater the risk }\end{array}$ \\
\hline & & GDP per capita $(\mathrm{C} 7)$ & $\begin{array}{l}\text { The better the index comment, } \\
\text { the lesser the risk }\end{array}$ \\
\hline & & Governance income and expenses (C8) & $\begin{array}{l}\text { The better the index comment, } \\
\text { the lesser the risk }\end{array}$ \\
\hline & & Total foreign trade (C9) & $\begin{array}{l}\text { The better the index comment, } \\
\text { the lesser the risk }\end{array}$ \\
\hline & & External debt $(\mathrm{C} 10)$ & $\begin{array}{l}\text { The better the index comment, } \\
\text { the greater the risk }\end{array}$ \\
\hline & \multirow{3}{*}{ Political alliance (B3) } & Alignment with power countries (C11) & $\begin{array}{l}\text { The better the index comment, } \\
\text { the greater the risk }\end{array}$ \\
\hline & & Affiliation with China (C12) & $\begin{array}{l}\text { The better the index comment, } \\
\text { the lesser the risk }\end{array}$ \\
\hline & & Trade with China (C13) & $\begin{array}{l}\text { The better the index comment, } \\
\text { the lesser the risk }\end{array}$ \\
\hline
\end{tabular}

it according to the qualitative data, their linguistic comments are always not unified.

Therefore, this paper will take "The Twenty-First Century Maritime Silk Road" as a typical case of human environment risk assessment and introduce it into the hesitant cloud model to quantify it to test the applicability of that model.

\subsection{Evaluation Experiment}

4.2.1. Indicator System Construction. The development level of the countries along The Twenty-First Century Maritime Silk Road is uneven. Firstly, the turbulence of national political situation and the replacement and instability of regime will bring risk to the investment. Secondly, the low-level of economic development will increase Chinese aid funds, which means the exposure of investment will be enhanced and its risk will increase. Furthermore, the attitude towards the Chinese strategic plan depends on its political tendency to a certain extent. The investment risk will be low when the country is in a neutral position.

To sum up, there are three aspects for the assessment as political situation, economic situation, and political alliance.

As for political situation, the civil war will be led by domestic political instability, exacerbating state division. Radically, corruption and administrative inefficiency are always the prime reason for that instability. As the contradictions become extremely fierce, the religious extremists tend to take the opportunity to rally and initiate terrorist activities to attempt to ban state political power. In the economic aspect, the proportion of poor people, gross domestic product per capita, governmental balance of payments, total foreign trade, and foreign debt can well represent the situation of a state economic. For the political alliance, alignment with power countries and the affiliation and trade with China are all the factors that should be taken into account as the indicators.

In conclusion, the indicator system for human environment risk of The Twenty-First Century Maritime Silk Road is shown as in Table 1, which includes target layer, first index layer, secondary indicator layer, and their properties. The properties of these indicators are brought in to illustrate the relationship of the indexes and human environment risk.

\subsubsection{Evaluation Based on Cloud Model}

(1) Construct Comments Set. Three experts are chosen to make comments on the risk level of these indicators. Linguistic comments of indicators $\mathrm{C} 1-\mathrm{C} 2$ and $\mathrm{C} 5-\mathrm{C} 13$ are made by expert $\mathrm{A}$ [29] and those of $\mathrm{C} 1-\mathrm{C} 8$ and $\mathrm{C} 10$ are given by expert $\mathrm{B}$ [30], while those of $\mathrm{C} 3-\mathrm{C} 4$ are made by expert $\mathrm{C}$ [31]. Therefore the comments sets of ten evaluated countries are shown as in Figure 2, in which the VL represents "very low," RL means "relatively low," ME signifies "medium," RH implies "relatively high," and VH stands for "very high."

(2) Set Up Linguistic Quantifiers. Express the comments in Table 2 by formulas (3) and (4) to set up linguistic quantifiers as shown in Table 3. 
TABLE 2: The comments sets for human environment risk of ten objective countries.

\begin{tabular}{|c|c|c|c|c|c|c|c|c|c|c|}
\hline & $\mathrm{A}$ & B & $\mathrm{C}$ & $\mathrm{D}$ & $\mathrm{E}$ & $\mathrm{F}$ & G & $\mathrm{H}$ & $\mathrm{I}$ & $\mathrm{J}$ \\
\hline $\mathrm{C} 1$ & $\mathrm{VL}, \mathrm{ME}$ & VL, RH & VL, RL & $\mathrm{VL}, \mathrm{ME}$ & $\mathrm{VH}$ & $\mathrm{VL}$ & $\mathrm{RH}$ & $\mathrm{RL}$ & $\mathrm{RH}$ & $\mathrm{VH}$ \\
\hline $\mathrm{C} 2$ & VL, RL & $\mathrm{VH}, \mathrm{VH}$ & VL, VL & $\mathrm{ME}, \mathrm{RH}$ & $\mathrm{RL}$ & $\mathrm{VL}$ & $\mathrm{ME}$ & $\mathrm{RL}$ & $\mathrm{RH}$ & ME \\
\hline $\mathrm{C} 3$ & $\mathrm{ME}, \mathrm{RL}$ & $\mathrm{RH}, \mathrm{ME}$ & VL, VL & VH, RH & $\mathrm{ME}$ & $\mathrm{RL}$ & $\mathrm{RH}$ & VH & $\mathrm{VH}$ & VH \\
\hline $\mathrm{C} 4$ & VL, RL & ME, RH & VL, VL & $\mathrm{ME}, \mathrm{ME}$ & $\mathrm{RL}$ & $\mathrm{RL}$ & $\mathrm{RH}$ & $\mathrm{ME}$ & $\mathrm{RL}$ & $\mathrm{RH}$ \\
\hline C5 & VL & RH & VL & $\mathrm{RH}$ & $\mathrm{VH}$ & $\mathrm{VL}$ & $\mathrm{RL}$ & $\mathrm{VL}$ & $\mathrm{VH}$ & $\mathrm{RH}$ \\
\hline C6 & VL, RL & ME, RH & VL, VL & $\mathrm{ME}, \mathrm{RH}$ & $\mathrm{RL}$ & $\mathrm{VL}$ & $\mathrm{RH}$ & $\mathrm{RH}$ & $\mathrm{VH}$ & $\mathrm{VH}$ \\
\hline $\mathrm{C} 7$ & $\mathrm{RL}, \mathrm{RL}$ & $\mathrm{RH}, \mathrm{ME}$ & VL, VL & $\mathrm{RH}, \mathrm{ME}$ & $\mathrm{ME}$ & $\mathrm{VL}$ & $\mathrm{RH}$ & $\mathrm{RH}$ & $\mathrm{VH}$ & $\mathrm{VH}$ \\
\hline $\mathrm{C} 8$ & $\mathrm{ME}, \mathrm{ME}$ & $\mathrm{VH}, \mathrm{ME}$ & $\mathrm{RL}, \mathrm{VL}$ & $\mathrm{RH}, \mathrm{ME}$ & $\mathrm{RH}$ & $\mathrm{VL}$ & $\mathrm{RH}$ & $\mathrm{ME}$ & $\mathrm{ME}$ & $\mathrm{RL}$ \\
\hline C9 & $\mathrm{RL}$ & ME & VL & $\mathrm{RL}$ & $\mathrm{RL}$ & $\mathrm{RL}$ & $\mathrm{ME}$ & $\mathrm{RL}$ & $\mathrm{RL}$ & ME \\
\hline $\mathrm{C} 10$ & $\mathrm{RL}, \mathrm{ME}$ & $\mathrm{RL}, \mathrm{RL}$ & VL, VL & VL, RL & $\mathrm{RL}$ & $\mathrm{VL}$ & $\mathrm{VH}$ & $\mathrm{RL}$ & $\mathrm{RH}$ & RL \\
\hline C11 & RH & RH & $\mathrm{RL}$ & $\mathrm{RH}$ & $\mathrm{VH}$ & $\mathrm{ME}$ & $\mathrm{VH}$ & $\mathrm{VL}$ & $\mathrm{VH}$ & $\mathrm{ME}$ \\
\hline $\mathrm{C} 12$ & $\mathrm{RL}$ & ME & $\mathrm{RL}$ & $\mathrm{ME}$ & $\mathrm{VL}$ & $\mathrm{RL}$ & $\mathrm{VH}$ & $\mathrm{VL}$ & $\mathrm{ME}$ & $\mathrm{RL}$ \\
\hline $\mathrm{C} 13$ & $\mathrm{RL}$ & $\mathrm{RL}$ & $\mathrm{RL}$ & VL & $\mathrm{VL}$ & $\mathrm{ME}$ & ME & $\mathrm{VL}$ & $\mathrm{RL}$ & $\mathrm{RL}$ \\
\hline
\end{tabular}

TABLE 3: Quantifiers of comments with digital characteristics of compatibility cloud.

\begin{tabular}{|c|c|c|c|c|c|}
\hline & A & $\mathrm{B}$ & $\mathrm{C}$ & $\mathrm{D}$ & $\mathrm{E}$ \\
\hline $\mathrm{C} 1$ & $\begin{array}{c}(0,0.067,0.005) \\
(0.5,0.033,0.005)\end{array}$ & $\begin{array}{c}(0,0.067,0.005) \\
(0.7,0.033,0.005)\end{array}$ & $\begin{array}{c}(0,0.067,0.005) \\
(0.3,0.033,0.005)\end{array}$ & $\begin{array}{c}(0,0.067,0.005) \\
(0.5,0.033,0.005)\end{array}$ & $(1,0.067,0.005)$ \\
\hline $\mathrm{C} 2$ & $\begin{array}{c}(0,0.067,0.005) \\
(0.3,0.033,0.005)\end{array}$ & $\begin{array}{l}(1,0.067,0.005), \\
(1,0.067,0.005)\end{array}$ & $\begin{array}{c}(0,0.067,0.005) \\
(0,0.067,0.005)\end{array}$ & $\begin{array}{c}(0.5,0.033,0.005) \\
(0.7,0.033,0.005)\end{array}$ & $(0.3,0.033,0.005)$ \\
\hline $\mathrm{C} 3$ & $\begin{array}{c}(0.5,0.033,0.005) \\
(0.3,0.033,0.005)\end{array}$ & $\begin{array}{c}(0.7,0.033,0.005) \\
(0.5,0.033,0.005)\end{array}$ & $\begin{array}{c}(0,0.067,0.005) \\
(0,0.067,0.005)\end{array}$ & $\begin{array}{c}(1,0.067,0.005) \\
(0.7,0.033,0.005)\end{array}$ & $(0.5,0.033,0.005)$ \\
\hline $\mathrm{C} 4$ & $\begin{array}{c}(0,0.067,0.005) \\
(0.3,0.033,0.005)\end{array}$ & $\begin{array}{c}(0.5,0.033,0.005) \\
(0.7,0.033,0.005)\end{array}$ & $\begin{array}{c}(0,0.067,0.005) \\
(0,0.067,0.005)\end{array}$ & $\begin{array}{c}(0.5,0.033,0.005) \\
(0.5,0.033,0.005)\end{array}$ & $(0.3,0.033,0.005)$ \\
\hline C5 & $(0,0.067,0.005)$ & $(0.7,0.033,0.005)$ & $(0,0.067,0.005)$ & $(0.7,0.033,0.005)$ & $(1,0.067,0.005)$ \\
\hline C6 & $\begin{array}{c}(0,0.067,0.005) \\
(0.3,0.033,0.005)\end{array}$ & $\begin{array}{c}(0.5,0.033,0.005) \\
(0.7,0.033,0.005)\end{array}$ & $\begin{array}{c}(0,0.067,0.005) \\
(0,0.067,0.005)\end{array}$ & $\begin{array}{c}(0.5,0.033,0.005) \\
(0.7,0.033,0.005)\end{array}$ & $(0.3,0.033,0.005)$ \\
\hline C7 & $\begin{array}{c}(0.3,0.033,0.005) \\
(0.3,0.033,0.005)\end{array}$ & $\begin{array}{c}(0.7,0.033,0.005) \\
(0.5,0.033,0.005)\end{array}$ & $\begin{array}{c}(0,0.067,0.005) \\
(0,0.067,0.005)\end{array}$ & $\begin{array}{c}(0.7,0.033,0.005) \\
(0.5,0.033,0.005)\end{array}$ & $(0.5,0.033,0.005)$ \\
\hline $\mathrm{C} 8$ & $\begin{array}{c}(0.5,0.033,0.005) \\
(0.5,0.033,0.005)\end{array}$ & $\begin{array}{c}(1,0.067,0.005) \\
(0.5,0.033,0.005)\end{array}$ & $\begin{array}{c}(0.3,0.033,0.005) \\
(0,0.067,0.005)\end{array}$ & $\begin{array}{c}(0.7,0.033,0.005) \\
(0.5,0.033,0.005)\end{array}$ & $(0.7,0.033,0.005)$ \\
\hline C9 & $(0.3,0.033,0.005)$ & $(0.5,0.033,0.005)$ & $(0,0.067,0.005)$ & $(0.3,0.033,0.005)$ & $(0.3,0.033,0.005)$ \\
\hline $\mathrm{C} 10$ & $\begin{array}{c}(0.3,0.033,0.005) \\
(0.5,0.033,0.005)\end{array}$ & $\begin{array}{c}(0.3,0.033,0.005) \\
(0.3,0.033,0.005)\end{array}$ & $\begin{array}{c}(0,0.067,0.005) \\
(0,0.067,0.005)\end{array}$ & $\begin{array}{c}(0,0.067,0.005) \\
(0.3,0.033,0.005)\end{array}$ & $(0.3,0.033,0.005)$ \\
\hline C11 & $(0.7,0.033,0.005)$ & $(0.7,0.033,0.005)$ & $(0.3,0.033,0.005)$ & $(0.7,0.033,0.005)$ & $(1,0.067,0.005)$ \\
\hline $\mathrm{C} 12$ & $(0.3,0.033,0.005)$ & $(0.5,0.033,0.005)$ & $(0.3,0.033,0.005)$ & $(0.5,0.033,0.005)$ & $(0,0.067,0.005)$ \\
\hline \multirow[t]{2}{*}{$\mathrm{C} 13$} & $(0.3,0.033,0.005)$ & $(0.5,0.033,0.005)$ & $(0.3,0.033,0.005)$ & $(0,0.067,0.005)$ & $(0,0.067,0.005)$ \\
\hline & $\mathrm{F}$ & G & $\mathrm{H}$ & I & $\mathrm{J}$ \\
\hline $\mathrm{C} 1$ & $(0,0.067,0.005)$ & $(0.7,0.033,0.005)$ & $(0.3,0.033,0.005)$ & $(0.7,0.033,0.005)$ & $(1,0.067,0.005)$ \\
\hline $\mathrm{C} 2$ & $(0,0.067,0.005)$ & $(0.5,0.033,0.005)$ & $(0.3,0.033,0.005)$ & $(0.7,0.033,0.005)$ & $(0.5,0.033,0.005)$ \\
\hline C3 & $(0.3,0.033,0.005)$ & $(0.7,0.033,0.005)$ & $(1,0.067,0.005)$ & $(1,0.067,0.005)$ & $(1,0.067,0.005)$ \\
\hline $\mathrm{C} 4$ & $(0.3,0.033,0.005)$ & $(0.7,0.033,0.005)$ & $(0.5,0.033,0.005)$ & $(0.3,0.033,0.005)$ & $(0.7,0.033,0.005)$ \\
\hline C5 & $(0,0.067,0.005)$ & $(0.3,0.033,0.005)$ & $(0,0.067,0.005)$ & $(1,0.067,0.005)$ & $(0.7,0.033,0.005)$ \\
\hline C6 & $(0,0.067,0.005)$ & $(0.7,0.033,0.005)$ & $(0.7,0.033,0.005)$ & $(1,0.067,0.005)$ & $(1,0.067,0.005)$ \\
\hline C7 & $(0,0.067,0.005)$ & $(0.7,0.033,0.005)$ & $(0.7,0.033,0.005)$ & $(1,0.067,0.005)$ & $(1,0.067,0.005)$ \\
\hline $\mathrm{C} 8$ & $(0,0.067,0.005)$ & $(0.7,0.033,0.005)$ & $(0.5,0.033,0.005)$ & $(0.5,0.033,0.005)$ & $(0.3,0.033,0.005)$ \\
\hline C9 & $(0.3,0.033,0.005)$ & $(0.5,0.033,0.005)$ & $(0.3,0.033,0.005)$ & $(0.3,0.033,0.005)$ & $(0.5,0.033,0.005)$ \\
\hline $\mathrm{C} 10$ & $(0,0.067,0.005)$ & $(1,0.067,0.005)$ & $(0.3,0.033,0.005)$ & $(0.7,0.033,0.005)$ & $(0.3,0.033,0.005)$ \\
\hline C11 & $(0.5,0.033,0.005)$ & $(1,0.067,0.005)$ & $(0,0.067,0.005)$ & $(1,0.067,0.005)$ & $(0.5,0.033,0.005)$ \\
\hline
\end{tabular}


TABLE 4: The digital characteristics of the compositive cloud for the ten objective countries.

\begin{tabular}{lccccc}
\hline & $\mathrm{A}$ & $\mathrm{B}$ & $\mathrm{C}$ & $\mathrm{D}$ & $\mathrm{E}$ \\
\hline B1 & $(0.207,0.119,0.005)$ & $(0.806,0.065,0.005)$ & $(0.033,0.08,0.005)$ & $(0.721,0.127,0.005)$ & $(0.62,0.047,0.005)$ \\
B2 & $(0.342,0.059,0.005)$ & $(0.685,0.139,0.005)$ & $(0.033,0.081,0.005)$ & $(0.486,0.085,0.005)$ & $(0.42,0.033,0.005)$ \\
B3 & $(0.433,0.033,0.005)$ & $(0.567,0.033,0.005)$ & $(0.3,0.33,0.005)$ & $(0.4,0.044,0.005)$ & $(0.333,0.067,0.005)$ \\
A1 & $(0.327,0.07,0.005)$ & $(0.686,0.079,0.005)$ & $(0.122,0.065,0.005)$ & $(0.535,0.086,0.005)$ & $(0.458,0.049,0.005)$ \\
\hline & F & G & H & I & J \\
\hline B1 & $(0.12,0.053,0.005)$ & $(0.58,0.033,0.005)$ & $(0.42,0.047,0.005)$ & $(0.74,0.047,0.005)$ & $(0.78,0.047,0.005)$ \\
B2 & $(0.06,0.06,0.005)$ & $(0.72,0.04,0.055)$ & $(0.5,0.033,0.005)$ & $(0.7,0.047,0.005)$ & $(0.62,0.047,0.005)$ \\
B3 & $(0.433,0.033,0.005)$ & $(0.833,0.056,0.005)$ & $(0,0.067,0.005)$ & $(0.6,0.044,0.005)$ & $(0.367,0.033,0.005)$ \\
A1 & $(0.204,0.049,0.005)$ & $(0.711,0.043,0.005)$ & $(0.307,0.049,0.005)$ & $(0.68,0.046,0.005)$ & $(0.589,0.042,0.005)$ \\
\hline
\end{tabular}

(3) Create Hesitant Cloud Set. As is discussed in Section 3.2, the hesitant fuzzy elements are relatively independent from each other and the comments of one expert are not easily influenced by other experts, so the HFWA operator would be the appropriate choice.

Then, aggregate Ex, En, He of the secondary indicator layers B1, B2, and B3, respectively, by HFWA operator. Taking country $\mathrm{A}$ as an example, the sixteen hesitant cloud sets generated from indicators $\mathrm{C} 1-\mathrm{C} 5$ of $\mathrm{B} 1$ are revealed as follows:

$(0.129,0.060,0.005), \quad(0.242,0.054,0.005), \quad(0.189$, $0.054,0.005), \quad(0.294,0.047,0.005), \quad(0.069,0.060$, $0.005), \quad(0.189,0.054,0.005), \quad(0.133,0.054,0.005)$, $(0.245,0.047,0.005), \quad(0.189,0.054,0.005), \quad(0.294$, $0.047,0.005), \quad(0.245,0.047,0.005), \quad(0.343,0.040$, $0.005), \quad(0.133,0.054,0.005), \quad(0.245,0.047,0.005)$, $(0.193,0.047,0.005),(0.297,0.040,0.005)$.

(4) Generate Compositive Cloud. Aggregate the indicators with superimposed comments due to multiple experts views belonging to $\mathrm{B} 1$ and $\mathrm{B} 2$ of countries $\mathrm{A}, \mathrm{B}, \mathrm{C}$, and $\mathrm{D}$. To retain experts opinions fully and perfectly, "soft or" algorithm (formula (3)) is brought in to integrate generated hesitant cloud set, while the float cloud algorithm (formula (2)) is introduced to synthesize other indicators due to their independence from each other. At last, because of the independence between B1, B2, and B3, a virtual linguistic term should be created in the blank area between the original clouds, so the float cloud algorithm (formula (2)) is also brought in to integrate them. Thus the digital characteristics of the compositive cloud for the ten objective countries are exhibited as in Table 4.

(5) Mapping from Digital Characteristics to Linguistic Comments. Create compositive cloud chart of linguistic term by forward normal cloud generator; that of country A is shown as in Figure 5.

The intervals of the basic group shadows (whose contribution to $u$ in the universe of discourse is $68.26 \%$ as Section 3 shows) will be considered as the results of assessment. As is revealed in Figure 3, the projection of basic group of the compositive risk cloud for country A locates in the relatively low risk interval. So the compositive risk of human environment of country A belongs to the relatively low risk level. The compositive risks of human environment of the ten

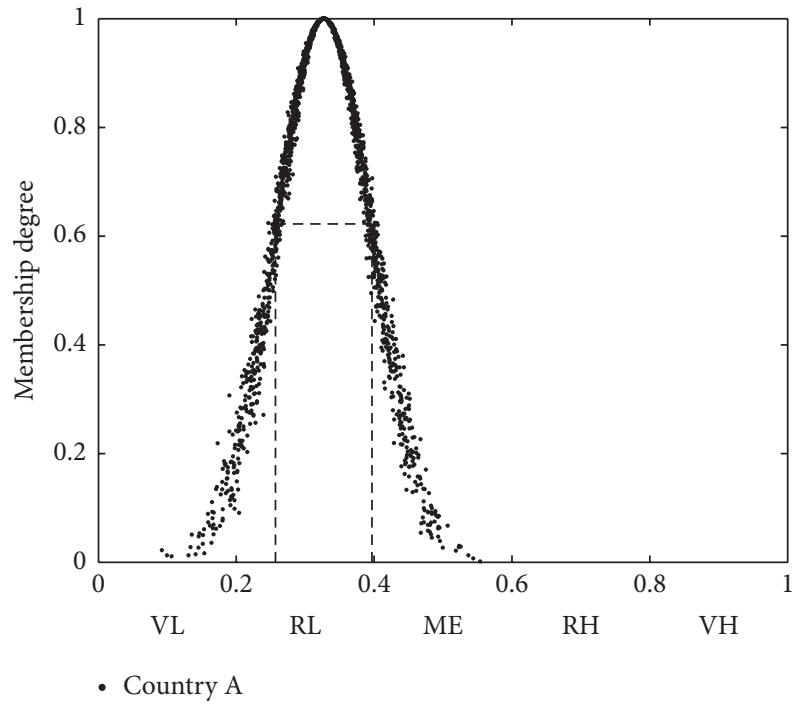

FIgURE 5: Cloud chart of compositive risk of country A.

TABLE 5: Linguistic comments on compositive risk of human environment of ten objective countries.

\begin{tabular}{rccccccccc}
\hline A & B & C & D & E & F & G & H & I & J \\
\hline Comments RL & RH & VL & ME & ME & MVL & RH & RL & RH & MH
\end{tabular}

countries can be obtained ditto in the light of the cloud chart, which is shown as in Table 5, In which the VL represents "very low," RL means "relatively low," ME signifies "medium," RH implies "relatively high," and VH stands for "very high." Besides, MVL represents "moderately very low," which locates between the VL and RL, and MH means "moderately high" which lies in the area between the ME and RL.

When the comments come to such linguistic terms as MVL and $\mathrm{MH}$, it means that the distribution probability of the projection of basic group is roughly equal to two adjacent intervals, and it is not rigorous to take it as either interval.

\section{Conclusion and Expectation}

This paper has proposed the hesitant cloud model on account of the general aporia of human environment risk, to deal with the situations that experts cannot make a complete comment 
on the whole indicator or cannot reach an agreement about a certain indicator. Then, the paper has taken the assessment for human environment risk of key areas of The Twenty-First Century Maritime Silk Road as an example, to testify the applicability of this model.

In the process of the above evaluation, sometimes the experts are not well acknowledged with the whole indicator system. By the traditional methods, the experts are always forced to make comments on all the indicators though they are not well known parts to them, or the assessor would give their comments on these indicators missing experts' comments. Therefore if the conventional methods were adopted, there will be some defects in the evaluation. On one hand, the consistency of data will be lost due to the deflection of the cognition on linguistic comments of diverse experts; on the other hand, only one comment is tolerated in one indicator, so the complete evaluation of experts cannot be well retained. However, the whole evaluation of all the experts can be reasonably integrated by the new modeling hesitant cloud model, by which means the acquired knowledge of the objects can be expressed completely and comprehensively, without the subjective opinion of the assessors. The quantitative evaluation result (the digital characteristics) can be projected into linguistic terms by the cloud generator; thus the merging of qualitative data is achieved.

Although the referred aporia in this paper of human environment risk assessment can be well solved by the hesitant cloud model, there are still some defects in the model. Firstly, the size of the hesitant cloud sets can be depicted as $l=\prod_{i=1}^{n} k_{i}$, which will increase with the number of experts, so does the computational load. If the number of indicators increases to four and the amount of experts is raised to five, then the size of generated hesitant cloud sets will reach to $5^{4}$. Secondly, the maturity of the model will change correspondingly with the integration of each compatibility cloud; like after the two compatibility clouds with different expectations are synthesized by floating-cloud algorithm the certainty of integrated cloud and the maturity of model will decrease. But maturity of the new cloud model can be calculated by the existing algorithm only according to the original cloud models. However, the influences of the integration algorithm on the new cloud model cannot be taken into account. For instance, because the maturity of original cloud models is equal, the maturity of the integrated cloud model is the same as them after the integration. However, the maturity of the new model will change in fact, as there are many simplifications in the process of computation.

\section{Competing Interests}

The authors declare that they have no competing interests.

\section{References}

[1] Y. Nishiwaki, H. Kawai, H. Morishima et al., "Possible Application of Fuzzy Set Theory in Risk Assessment, Subjective Perception and Public Attitude Study on Nuclear Energy[DB/OL]," http://www.irpa.net/irpa6/cdrom/VOL.3/B3_90.PDF.
[2] L. Pokorádi, "Application of fuzzy set theory for risk assessment," Journal of Konbin, vol. 14-15, pp. 187-196, 2010.

[3] P. Dutta and T. Ali, "Uncertainty modeling in risk analysis: a fuzzy set approach," International Journal of Computer Applications, vol. 43, no. 17, pp. 35-39, 2012.

[4] N. S. Arunraj, S. Mandal, and J. Maiti, "Modeling uncertainty in risk assessment: an integrated approach with fuzzy set theory and Monte Carlo simulation," Accident Analysis and Prevention C, vol. 55, no. 3, pp. 242-255, 2013.

[5] Y. Chen, L. Shu, and T. J. Burbey, "An integrated risk assessment model of township-scaled land subsidence based on an evidential reasoning algorithm and fuzzy set theory," Risk Analysis, vol. 34, no. 4, pp. 656-669, 2014.

[6] D. Li, Artificial Intelligence with Uncertainty, National Defense Industry Press, Beijing, China, 2014.

[7] D. Li, H. Meng, and X. Shi, "Membership clouds and membership cloud generators," Journal of Computer Research \& Development, vol. 32, no. 6, pp. 15-20, 1995.

[8] L. Qin and L. I. Bing, "Novel method of uncertain data modeling and classification based on cloud model," Computer Science, vol. 41, no. 8, pp. 233-240, 2014.

[9] G. Wang, C. Xu, and D. Li, "Generic normal cloud model," Information Sciences, vol. 280, pp. 1-15, 2014.

[10] V. Torra and Y. Narukawa, "On hesitant fuzzy sets and decision," in Proceedings of the IEEE International Conference on Fuzzy Systems, pp. 1378-1382, Jeju Island, Republic of Korea, August 2009.

[11] V. Torra, "Hesitant fuzzy sets," International Journal of Intelligent Systems, vol. 25, no. 6, pp. 529-539, 2010.

[12] Z. Xu and M. Xia, "Distance and similarity measures for hesitant fuzzy sets," Information Sciences, vol. 181, no. 11, pp. 2128-2138, 2011.

[13] Z. Xu and M. Xia, "On distance and correlation measures of hesitant fuzzy information," International Journal of Intelligent Systems, vol. 26, no. 5, pp. 410-425, 2011.

[14] B. Zhu, Z. Xu, and M. Xia, "Dual hesitant fuzzy sets," Journal of Applied Mathematics, vol. 2012, Article ID 879629, 13 pages, 2012.

[15] N. Chen and Z. Xu, "Properties of interval-valued hesitant fuzzy sets," Journal of Intelligent \& Fuzzy Systems, vol. 27, no. 1, pp. 143158, 2014.

[16] T. González-Arteaga, J. C. R. Alcantud, and R. D. Andrés, "New correlation coefficients for hesitant fuzzy sets," in Proceedings of the Conference of the International Fuzzy Systems Association and the European Society for Fuzzy Logic and Technology (IFSAEUSFLAT '15), Gijón, Spain, June 2015.

[17] R. M. Rodríguez, L. Martínez, V. Torra, Z. S. Xu, and F. Herrera, "Hesitant fuzzy sets: state of the art and future directions," International Journal of Intelligent Systems, vol. 29, no. 6, pp. 495-524, 2014.

[18] R. M. Rodríguez, B. Bedregal, H. Bustince et al., "A position and perspective analysis of hesitant fuzzy sets on information fusion in decision making. Towards high quality progress," Information Fusion, vol. 29, pp. 89-97, 2016.

[19] F. Herrera, L. Martínez, V. Torra, and Z. Xu, "Hesitant fuzzy sets: an emerging tool in decision making," International Journal of Intelligent Systems, vol. 29, no. 6, pp. 493-494, 2014.

[20] T. Rashid and S. M. Husnine, "Multicriteria group decision making by using trapezoidal valued hesitant fuzzy sets," The Scientific World Journal, vol. 2014, Article ID 304834, 8 pages, 2014. 
[21] M. Xia, Z. Xu, and N. Chen, "Some hesitant fuzzy aggregation operators with their application in group decision making," Group Decision and Negotiation, vol. 22, no. 2, pp. 259-279, 2013.

[22] C. Wei, Z. Ren, and R. M. Rodríguez, "A hesitant fuzzy linguistic TODIM method based on a score function," International Journal of Computational Intelligence Systems, vol. 8, no. 4, pp. 701712, 2015.

[23] Q. Si and M. C. Li, "Application of cloud theory and set pair analysis coupled model for evaluating environmental carrying capacity in Tianjin," Applied Mechanics and Materials, vol. 675677, pp. 377-381, 2014.

[24] X. Zou, "Research on comprehensive evaluation of CCS project based on integrated cloud model and entropy weight," International Journal of Nonlinear Science, vol. 18, no. 1, pp. 53-59, 2014.

[25] R. Jiang, D. Li, and J. Fan, "Automatic generation of pan-concept-tree on numerical data," Chinese Journal of Computers, vol. 23, no. 5, pp. 470-476, 2000.

[26] K. T. Atanassov, "Intuitionistic fuzzy sets," Fuzzy Sets and Systems, vol. 20, no. 1, pp. 87-96, 1986.

[27] I. B. Turksen, "Interval valued fuzzy sets based on normal forms," Fuzzy Sets and Systems, vol. 20, no. 2, pp. 191-210, 1986.

[28] Z. Xu, Hesitant Fuzzy Sets Theory, vol. 314 of Studies in Fuzziness and Soft Computing, Springer, Berlin, Germany, 2014.

[29] Think China, Study on the political risk of the investment in the "One-Belt-and-One-Road", 2015, http://think.china.com.cn.

[30] J. Birkmann, S. L. Cutter, D. S. Rothman et al., "Scenarios for vulnerability: opportunities and constraints in the context of climate change and disaster risk," Climatic Change, vol. 133, no. 1, pp. 53-68, 2015.

[31] Transparency International Group, "Corruption Perceptions Index," 2014, http://www.transparency.org/. 


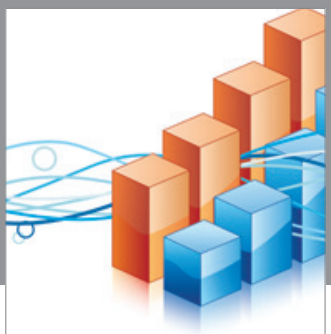

Advances in

Operations Research

vatem alat4

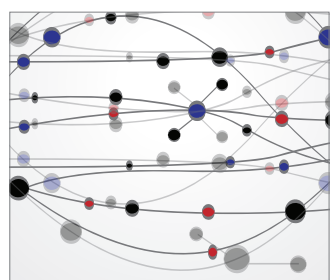

\section{The Scientific} World Journal
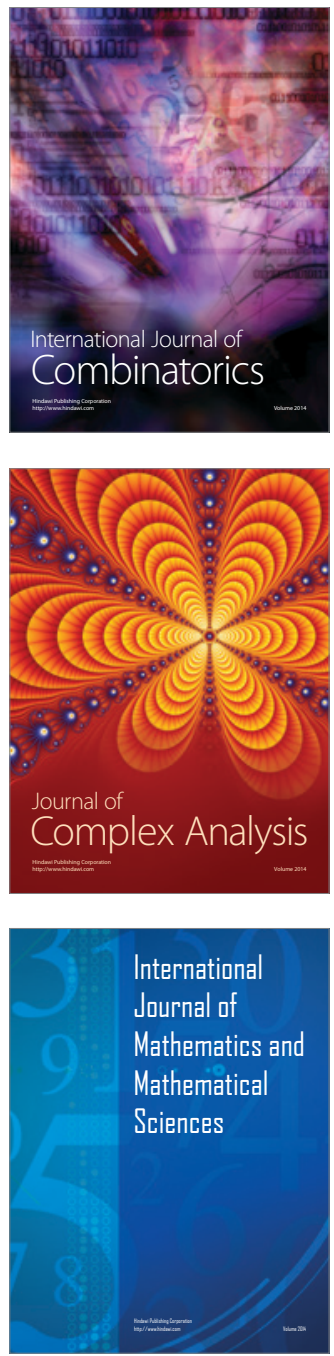
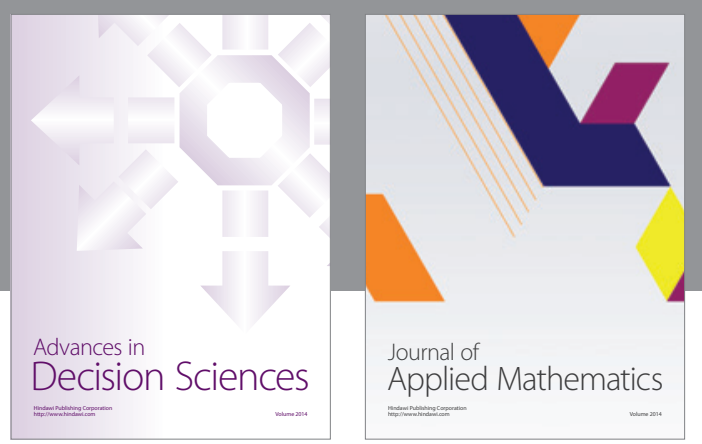

Algebra

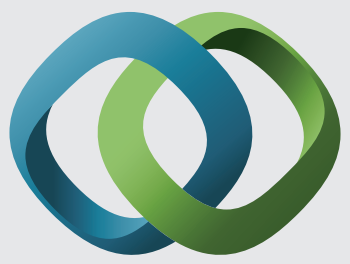

\section{Hindawi}

Submit your manuscripts at

http://www.hindawi.com
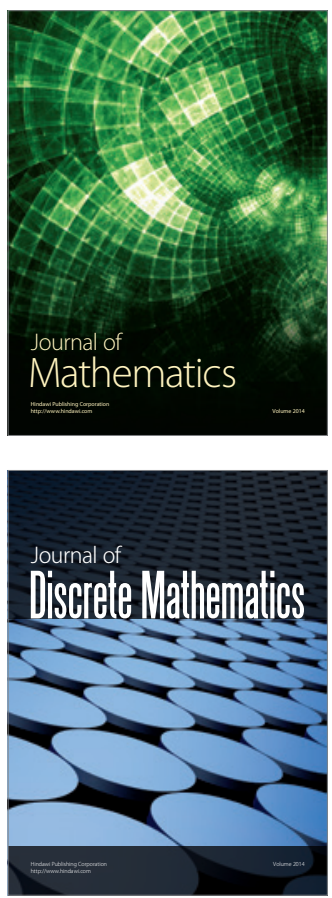

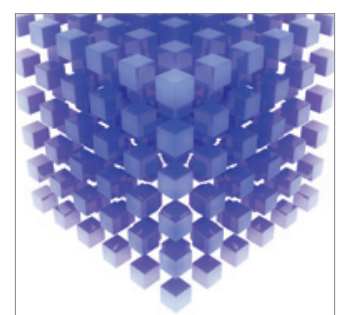

Mathematical Problems in Engineering
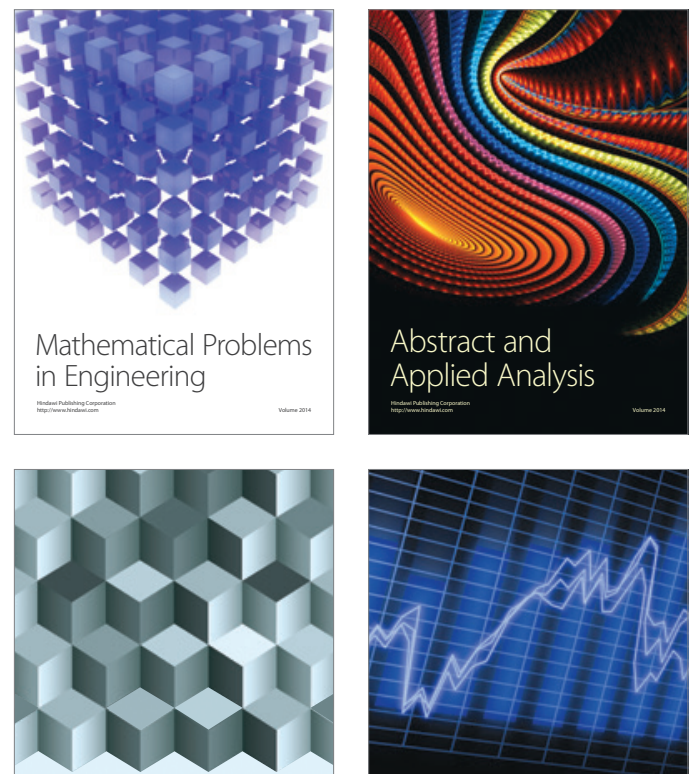

Journal of

Function Spaces

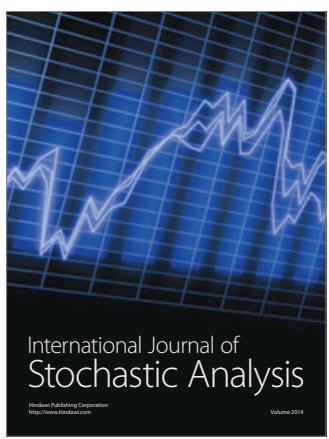

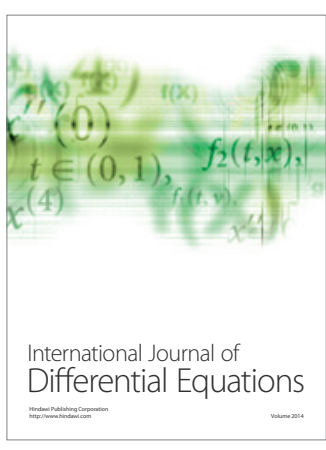
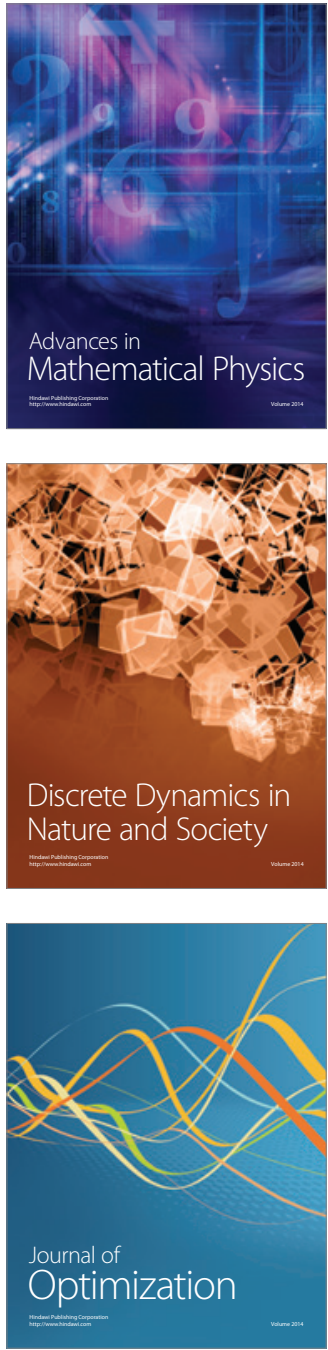